\title{
ESCREVER O DISCURSO DE OUTROS, COM OUTROS: UMA EXPERIÊNCIA IMANENTE DE ESCRITA-PESQUISA
}

\author{
ESCRIBIR EL DISCURSO DE OTROS, CON OTROS: \\ UNA EXPERIENCIA INMANENTE DE ESCRITURA-INVESTIGACIÓN
}

\section{WRITING THE SPEECH OF OTHERS WITH OTHERS: AN IMMANENT WRITING- RESEARCH EXPERIENCE}

\author{
HEUSER, Ester Maria Dreher \\ esterheu@hotmail.com \\ UNIOESTE - Universidade Estadual do Oeste do Paraná \\ https://orcid.org/0000-0002-1762-7526 \\ DIAS, Adriana Muniz \\ filoadri2008@hotmail.com \\ SEED/PR - Secretaria Estadual de Educação do Paraná \\ https://orcid.org/0000-0001-5782-9475 \\ SCIENZA, Roberto Corrêa \\ robcorreasc@gmail.com \\ UNIOESTE - Universidade Estadual do Oeste do Paraná \\ https://orcid.org/0000-0002-6275-7047
}

\begin{abstract}
RESUMO $O$ artigo se ocupa dos supostos conceituais presentes em algumas experiências de escrita-pesquisa em Filosofia que visaram a "fazer o múltiplo", dentre elas, esta escritura. A noção de imanência é o solo sobre o qual o artigo é produzido com vistas a responder quais são as noções complexas que condicionam essas experiências reais de escrever com outros, as quais dependem da operação $n-1$. Com Bakhtin, evidencia-se a presença da indissociabilidade do dialogismo e do outro no discurso; problematizam-se os destinos dados pela tradição platônica à diferença e explicitam-se os esforços de Deleuze para pensar a sua natureza própria e trazer à luz um mundo de diferenças livres, de devires que tornam possível a expressão de outrem como mundo possível; e mais: enfrenta-se o problema do estilo como agenciamento de enunciação, procedimento de variação contínua, avaliando-se o que se passou nos participantes dessa experiência imanente.
\end{abstract}

Palavras-Chave: Deleuze. Diferença. Estilo. Imanência. $n$-1. Outrem.

RESUMEN El artículo se ocupa de los supuestos conceptuales presentes en algunas experiencias de escritura-investigación en Filosofía que pretendieron "hacer el múltiplo", entre ellos, esta escritura misma. La noción de inmanencia es el suelo sobre el cual el artículo es producido con el propósito de responder cuáles son las nociones complejas que condicionan esas experiencias reales de escribir con otros. Bajtín, por ejemplo, evidencia la presencia de la insociabilidad del dialogismo y del otro en el discurso, además de problematizar los destinos dados por la tradición platónica a la diferencia y mostrar los esfuerzos de Deleuze para pensar su naturaleza propia y traer 
a la luz un mundo de diferencias libres de devenires que hacen posible la expresión del otro como mundo posible. De ese modo, se enfrenta al problema del estilo como agenciamiento de enunciación y procedimiento de variación continua para se pueda evaluar lo que pasó en los participantes de esa experiencia inmanente.

Palabras clave: Deleuze. Diferencia. Estilo. Inmanencia. $n-1$. Outrem.

ABSTRACT The article deals with the conceptual assumptions present in some writing-research experiences in Philosophy that aimed to "make the multiple", among them, this scripture. The concept of immanence is the soil upon which the article is produced in order to answer what are the complex notions that condition these actual experiences of writing with others, which depend on the operation $n-1$. The article shows the presence of the inseparability of dialogism and of the Other in discourse with Bakhtin; It problematizes the destinies given by the Platonic tradition to the difference and it show the efforts of Deleuze to think difference's own nature and to bring to light a world of free differences, becomings that make possible the expression of the Other as a possible world. Lastly, the article faces the problem of style as agency of enunciation, procedure of continuous variation, evaluating what happened in the participants of this immanent experience.

Keywords: Deleuze. Difference. Style. Immanence. $n-1$. Other.

\section{EXPERIMENTAR UMA ESCRITA-PESQUISA A $n-1$}

A Universidade é, por excelência, lugar de hierarquias. Talvez seja a instituição em que o sonho platônico do governo dos sábios melhor se efetive. Nela, a imagem do mundo verticalizado se mostra sem disfarces, nos cargos e nos currículos, nas disposições geográficas, nas distribuições territoriais e financeiras, nas relações interpessoais, nas aulas, palestras e congressos. Entretanto, por meio de alguns intercessores e procedimentos, esse "universo em escada" é capaz de engendrar uma anarquia particular e promover, em alguns interstícios institucionais, uma aventura da imanência que estabelece concorrência com a transcendência.

"Uma inspiração totalmente outra atravessa esse cosmos" (DELEUZE, 2016a, p. 277) acadêmico hierárquico: entre os níveis dos degraus, algo se passa capaz de produzir pensamentos, relações e textos ricos de novas composições feitas de ideias alheias, advindas da filosofia, da literatura, das artes e das ciências. Mas não se trata de, unicamente, escrever em meio a uma solidão povoada, de produzir incutindo outro sujeito de enunciação, como permite a forma sintática singular do discurso indireto livre (DELEUZE, 2016b). A "inspiração totalmente outra" a que nos referimos é a de levar ao pé da letra o desafio lançado por Deleuze e Guattari, a saber: "Na verdade 
não basta dizer Viva o múltiplo [...]. Nenhuma habilidade tipográfica, lexical ou mesmo sintática será suficiente para fazê-lo ouvir. É preciso fazer o múltiplo [...]" (DELEUZE; GUATTARI, 2004, p. 14, grifos nossos).

Esse desafio é lançado por Deleuze e Guattari (2004) quando apresentam duas imagens de livro e de mundo, as quais cabem bem para caracterizar imagens de pensamento na universidade e maneiras de escrever artigos acadêmicos: a imagem de pensamento arbórea, que produz, dentre outras coisas, hierarquias, transcendências e o livro-raiz pivotante, incapazes de compreenderem a multiplicidade; e a imagem de pensamento rizomática, produtora de livros-rizomas que supõem a multiplicidade, a qual não se deixa sobrecodificar nem fechar-se em si mesma, uma vez que sua existência necessita do fora, de relações horizontais e transversais, assim como da imanência imanente a si mesma (DELEUZE, 2016c).

Assumimos para nós o desafio: experimentar fazer o múltiplo e, consequentemente, deixar morrer, por desidratação, as raízes pivotantes e as fasciculadas - sistemas que designam tão bem os títulos e as relações na academia, cujas raízes são hidratadas, hierarquicamente, por iniciantes na pesquisa, mestrandos, doutorandos, pós-doutorandos, líderes de pesquisas e a burocracia. A fórmula para isso está indicada no Platô Rizoma (DELEUZE; GUATTARI, 2004, p. 15): "n-1".

O primeiro passo, para tanto, foi subtrair a hierarquia do estudo a ser feito e do modo de produzir o texto por vir, para então experimentar uma escrita-pesquisa a $n$ 1. Depois, parafraseando Deleuze e Guattari (2004, p. 12), ter, ao escrever, como única questão, saber "com quais outras máquinas a máquina de escrita acadêmica pode estar ligada para funcionar?". Assim, juntos descobrimos que a máquina de escrita-pesquisa funciona melhor em bando e pode, também, ser isso "fazer o múltiplo": escrever rizomaticamente e, suplementarmente, viver a vida na universidade com mais alegria, aumentando nossa potência, para dentro e para fora da academia, a cada aventura de escrita-pesquisa.

Este artigo, produzido por muitas mãos que trabalham ao mesmo tempo - em uma relação horizontal, em termos interpessoais; transversal, em termos de conteúdos e matérias advindas de diferentes formas de pensamento; e rizomática, em termos de procedimentos de escrita -, na plataforma Google drive (serviço de 
armazenamento virtual de dados), por meio da ferramenta Google Docs (processador de texto), trata de uma dessas aventuras que vem sendo vivenciada em um grupo de orientação e pesquisa (orientadora, orientandos e ex-orientandos) do Curso de PósGraduação em Filosofia da Universidade Estadual do Oeste do Paraná, na Linha de Ética e Filosofia Política. Esse grupo ocupa-se, principalmente, da filosofia de Gilles Deleuze, mobilizando-se por ímpetos de imanência que transgridem o mundo vertical acadêmico e tomam-no às avessas.

A produção deste artigo é parte da referida aventura - iniciada em 2017 na preparação para a apresentação do Platô 3, "Geologia da moral. Quem a Terra pensa que é?", de Deleuze e Guattari (2004), a qual teve lugar no "Sem Mil Platôs: foge-se no mesmo lugar", no Instituto Federal Sul-Riograndense (IFSul), campus Pelotas; continuada em 2018, durante a preparação para a apresentação do Platô 5, "Sobre alguns regimes de signos" (DELEUZE; GUATTARI, 2011), ocorrida na Universidade Federal do Rio Grande do Sul (UFRGS), Faculdade de Educação, no "Seminário Especial Mil Platôs, vol. 2", eventos organizados pela Rede de Pesquisas "Escrileituras da Diferença em Filosofia-Educação". Com este artigo, temos a primeira oportunidade para indagar e refletir sobre o que se passou e o que foi feito; dar a ver, sobretudo, os supostos que estiveram presentes neste e nos referidos trabalhos, os quais são sua condição de efetividade, em termos de procedimentos de investigação coletiva presentes nas experiências imanentes de escrita-pesquisa; e, quiçá, servir para outros que se embrenham nos estudos da diferença, tal como propõe este dossiê Modos de escrever, inventar e criar com a diferença: a cartografia e outras metodologias afins.

Como já se pôde perceber, a noção de imanência é o solo sobre o qual essa tessitura se produz (DELEUZE, 2016a, 2016c). Diferente do que se pode supor, este artigo não é um "relato de experiência", antes, ele é, como já indicado, um movimento coletivo de tornar objetivo, primeiro, para nós, depois, para os leitores interessados em variações dos modos de pesquisar e escrever, o que está suposto nas experiências de escrita-pesquisa que temos realizado. Responder quais são as noções complexas que condicionam essas experiências reais de escrever os discursos dos outros, com outros é o objetivo principal deste artigo. 
Com Bakhtin (1997; 2006), evidenciamos a presença da indissociabilidade do dialogismo e do outro no discurso próprio ao devir da filosofia, o qual carrega consigo vozes polêmicas promotoras de uma polifonia na qual múltiplas vozes se defrontam e se entrechocam; problematizamos os destinos dados pela tradição platônica à diferença e mostramos os esforços de Deleuze (1988; 2007) para pensar a sua natureza própria, desvinculada da identidade e da representação, e trazer à luz um mundo de diferenças livres, de devires que tornam possível a expressão de outrem como mundo possível.

Considerando que a diferença livre propicia um pouco de anarquia em nós, a qual nos permite desviarmos das hierarquias acadêmicas e produzirmos devires para escrever em bando, enfrentamos o problema do estilo como agenciamento de enunciação, procedimento de variação contínua, que se diferencia de uma criação psicológica individual, especialmente a partir dos platôs da linguagem (DELEUZE; GUATTARI, 2011). Por fim, e brevemente, avaliamos o que se passou nos autores que participaram dessa experiência imanente, especialmente no que se refere aos efeitos de uma formação pela e para a escrita-pesquisa rizomática e imanente que recusa a lógica determinada pela tradição platônica de um "universo escalonado", orientado por um princípio transcendente que opera por uma série de conversões hierárquicas e acaba constituindo o "perfil" do pesquisador.

\section{O OUTRO QUE NOS HABITA E A POLIFONIA DA DIFERENÇA}

Um texto nunca é inofensivo. Textos já revelaram descobertas incríveis, mudaram o curso da história e transformaram sociedades inteiras. Aliás, qualquer enunciado que seja jamais é despretensioso. Segundo Bakhtin (2006), a linguagem é um lugar de disputas ideológicas, pois revela diversas concepções de mundo. Para o autor, a linguagem tem como fundamento o dialogismo. Ela revela uma abertura para o outro que é, ao mesmo tempo, presente e parte integrante de qualquer ato enunciativo. A vida é, pois, um processo dialógico e viver significa estar em um diálogo, do qual 
todo na palavra, e esta palavra entra no tecido dialógico da existência humana, no simpósio universal. (BAKHTIN, 1997, p. 348).

O dialogismo de Bakhtin revela uma situação e meio sociais imediatos. Não há sujeito adâmico, isto é, um primeiro homem a dizer as primeiras palavras dotadas de um primeiro sentido (BAKHTIN, 2006). O conceito de dialogismo entende a palavra como dotada de um constante movimento. $\mathrm{O}$ discurso faz parte de um continuum. Ele é integrante de um processo social (BAKHTIN, 1997). Tomando o social como inseparável da enunciação, Bakhtin põe em questão a suposta objetividade da representação e estabelece, portanto, um deslocamento da relação eu-outro.

Segunda subtração, após a supressão da hierarquia, que precisamos operar para escrever em bando: subtrair o sujeito centrado para, então, experimentar uma escrita-pesquisa a $n-1$. O eu não existe, então, senão como abertura para o outrem. Para Bakhtin, a própria ideia de identidade é construída a partir do outro. O processo de humanização é feito por meio da linguagem e esta é sempre alheia. Habitamos um mundo constituído pelas palavras do outro, sendo a vida reação ao outro: relação.

Tudo o que me diz respeito, a começar por meu nome, e que penetra em minha consciência, vem-me do mundo exterior, da boca dos outros (da mãe), etc., e me é dado com a entonação, com o tom emotivo dos valores deles. Tomo consciência de mim, originalmente, através dos outros: deles recebo a palavra, a forma e o tom que servirão à formação original da representação que terei de mim mesmo (BAKHTIN, 1997, p. 378).

O filósofo russo vai além. Também traz consigo um novo conceito quando trabalha textos de Dostoiévski. Para Bakhtin (2013), Dostoiévski é o criador do romance polifônico, conceituado como um texto constituído por vozes polêmicas de diferentes e contraditórias ideologias. Segundo o autor, todo discurso resulta de uma trama de vozes diversas. O dialogismo bakhtiniano toma o mundo e seu discurso como polifônico, sendo o outro uma presença constante e inerente a ambos. A linguagem, logo, mostra-se como uma realidade intersubjetiva e dialógica. Nela, não há um indivíduo completo e fechado. Ele é atravessado pela coletividade. Discurso indireto livre: em todo sujeito que enuncia algo estão contidos "outros que falam, cada qual uma língua diversa, umas nas outras. É o discurso indireto livre que conduz Bakhtin à sua concepção polifônica ou contrapontística da língua no romance" 
(DELEUZE, 2016c, p. 389). Assim, o princípio dialógico afirma a alteridade como inerente a qualquer processo humano.

\begin{abstract}
Os valores vinculados à existência da pessoa, determinada por suas propriedades, só concernem ao outro. Apenas o outro torna possível a alegria que sentirei ao encontrá-lo, ao estar com ele, o pesar que sentirei ao deixálo, a dor que sentirei ao perdê-lo; e é somente com ele que posso encontrarme e somente dele que posso separar-me no espaço temporal. Quanto a mim, estou sempre comigo, para mim não poderia haver vida sem mim. Todos esses valores emotivo-volitivos só são possíveis com relação ao outro, e eles dão à sua vida um peso de acontecimento particular que minha própria vida não tem. Não se trata de graus de um valor, mas da natureza das propriedades desse valor. O tom emotivo-volitivo parece contribuir para dar consistência ao outro e particulariza a vivência que tenho do todo da sua vida, dá colorido emocional a esse todo. Em minha vida, os seres nascem, passam e morrem, e a vida/morte deles é muitas vezes o acontecimento mais importante da minha vida, o acontecimento que determina seu conteúdo (o que é o essencial do romanesco na literatura universal). Esse caráter de acontecimento significante não é concedido à minha própria vida: minha vida é o que engloba, no tempo, a existência do outro (BAKHTIN, 1997, p. 120).
\end{abstract}

Há um outro que nos habita. Que é parte de nós. Que nos olha por todos os lados. Que nos constitui enquanto "eus". Que nos transforma e é transformado por nós. Que nos compõe e desconstrói. Que é absorvido, mas polemizado por nós. As composições de alteridade são complicadas. Problemáticas. Revelam contradições e conflitos que podem nunca ser superados. Isso porque o mundo é polifônico; um mundo múltiplo de diferentes vozes. Vozes polêmicas. Um mundo de diferença.

A diferença sempre foi polêmica. Isso se deve ao fato de, durante grande parte da história da filosofia, ter sido subordinada à identidade, tomada como uma cópia mal fundada desta. Deleuze (1988) mostra que quem inaugurou esse pressuposto foi Platão ${ }^{1}$. De acordo com ele, a filosofia platônica fez o pensamento se atrelar aos seus pressupostos tão fortemente, a ponto de impedir o movimento para fora deles. $\mathrm{O}$ francês denuncia que o pensamento platônico estabelece a si mesmo por meio do conceito de Ideia - sendo ela seu modelo e fundamento. Para Platão, apenas a Ideia de Justiça é justa e não outra coisa, por exemplo. Somente a Ideia de Liberdade pode ser plenamente livre e não outra coisa. O grego refere o mundo suprassensível como o terreno próprio das Ideias; um plano perfeito. O mundo sensível, por outro lado, é

1 Embora haja intérpretes de Platão que pensem sua filosofia em relação à diferença de um modo afirmativo, como é o caso de Marcelo Pimenta Marques (2006), que se demora em analisar o lugar e importância do outro (thateron e heteron) no diálogo Sofista, nossa leitura se atém, deliberadamente, à perspectiva deleuziana, que afirma a subordinação da diferença à identidade. 
tomado como degenerado e corrompido. Nada que se extraia dele pode se elevar ao estatuto de Ideia. É disso que trata, em suma, sua famosa "Alegoria da caverna". Platão (2000, 516a) atribui, de um lado, ao mundo suprassensível o Sol, a Luz, a Verdade e o Conhecimento e, de outro, ao mundo sensível as sombras, o engano, a falsidade e a ignorância.

Todavia, Platão não para por aí. O filósofo grego ainda estabelece que a própria concepção do mundo sensível só é possível em função do mundo suprassensível, a "fonte imediata da verdade e da inteligência" (PLATÃO, 2000, p. 323, 517c). O mundo sensível e tudo o que nele se manifesta são tomados como cópias. Tudo que há nele só existe em função de modelos perfeitos, de ideias que habitam o mundo suprassensível. Seu pressuposto, a Ideia, leva Platão a um verdadeiro combate às cópias. Há agora graus de proximidade e semelhança das cópias em relação à coisa em si. Há o Mesmo, o semelhante e a 'maldita' diferença. Platão quer selecionar os pretendentes. Estabelecer quais são bons e quais são ruins, falsos ou impuros. Não se trata mais de meras cópias, mas de cópias degeneradas - os chamados simulacros.

O platonismo é a Odisséia filosófica; a dialética platônica não é uma dialética da contradição nem da contrariedade, mas uma dialética da rivalidade (amphisbetesis), uma dialética dos rivais ou dos pretendentes. A essência da divisão não aparece em largura, na determinação das espécies de um gênero, mas em profundidade, na seleção da linhagem. Filtrar as pretensões, distinguir o verdadeiro pretendente dos falsos (DELEUZE, 2007, p. 260).

O simulacro, assim, torna-se o monstro a ser mantido no fundo do oceano. Uma cópia em seu mais alto grau de degeneração, a ponto de diferir absolutamente do modelo padrão, de sua suposta identidade. Ele implica grandes dimensões, há um devir-louco, ilimitado, sempre outro. Um devir subversivo das profundidades que escapa ao Mesmo ou ao semelhante. O simulacro é construído sobre uma disparidade, sobre uma diferença. Assim, não pode ser definido em relação ao modelo. A teoria das Ideias é abalada. O mundo pode não funcionar pela lógica modelo-cópia, e ainda assim funcionar. Platão sabe disso: "Platão, no clarão de um instante, descobre que não é simplesmente uma falsa cópia, mas que põe em questão as próprias noções de cópia e de modelo" (DELEUZE, 2007, p. 261). Aliás, "se o 


\section{Atos de Pesquisa em Educação - ISSN 1809-0354 \\ Blumenau, v.14, n.3, p.982-1005, set./dez. 2019 \\ DOI: http://dx.doi.org/10.7867/1809-0354.2019v14n3p982-1005}

simulacro tem ainda um modelo, trata-se de um outro modelo, um modelo do Outro de onde decorre uma dessemelhança interiorizada" (DELEUZE, 2007, p. 263).

A caça às bruxas então começa. Segundo Deleuze (1988, p. 420), "o que é condenado no simulacro é o estado das diferenças livres oceânicas, das distribuições nômades, das anarquias coroadas, toda esta malignidade que contesta tanto a noção de modelo quanto a de cópia”. Diante do devir-louco do simulacro, a vontade platônica é a de "impor um limite a este devir, ordená-lo ao mesmo, torná-lo semelhante - e, para a parte que permaneceria rebelde, recalcá-la o mais profundo possível, encerrála numa caverna no fundo do Oceano" (DELEUZE, 2007, p. 264).

Para Deleuze (1988), é evidente a vontade do platonismo: eliminar os simulacros. Excluir o divergente, o excêntrico, o subversivo, isso para assegurar a vitória das cópias - que são "pretendentes bem fundados", porque semelhantes ao modelo - sobre os simulacros, que implicam uma perversão e "um desvio essenciais", porque "construídos a partir de uma dissimilitude" da própria diferença. Na perspectiva platônica, é preciso "assegurar o triunfo das cópias sobre os simulacros, de recalcar os simulacros, de mantê-los encadeados no fundo, de impedi-los de subir à superfície e de se 'insinuar' por toda parte” (DELEUZE, 2007, p. 262).

O simulacro é a diferença que não pode ser forçada a se enquadrar nas categorias da representação. Que não pode ser controlada ou se adequar ao "modelo perfeito" estabelecido pela representação. Segundo Deleuze (1988), o conceito de diferença, na lógica da representação, foi pensado a partir das ideias de igualdade e semelhança. Sempre subordinado à identidade. Para o autor, o pensamento da representação nunca pensou a diferença de maneira independente, separada de um conceito geral do qual ela difere. Ela foi sempre vista como a variação do geral, a negação da identidade. Subordinada ao Mesmo ou ao semelhante. Tomada como uma oposição até a sua contradição, a partir de uma analogia, ou reduzida ao negativo que deve ser superado.

Deleuze (1988) critica a tradição platônica da filosofia e afirma a natureza da diferença, que está distante de um modelo, desligada do Mesmo e da identidade. Para tanto, ela precisa ser pensada em si mesma, o que implica não estar submetida às exigências da representação. Do contrário, perde sua natureza - a multiplicidade. Ao emergir das profundezas oceânicas, a diferença se mostra como primeira, pois "há 


\section{Atos de Pesquisa em Educação - ISSN 1809-0354 \\ Blumenau, v.14, n.3, p.982-1005, set./dez. 2019 \\ DOI: http://dx.doi.org/10.7867/1809-0354.2019v14n3p982-1005}

tão-somente a variedade de multiplicidade, isto é, a diferença, em vez da enorme oposição do uno e do múltiplo. E talvez seja uma ironia dizer: tudo é multiplicidade, mesmo o uno, mesmo o múltiplo" (DELEUZE, 1988, p. 297). A submissão da diferença às categorias da representação acaba por anular a diferença tomada por ela mesma, enquanto múltipla e diversa.

Consequentemente, esse pensamento passa a se estender por toda e qualquer alteridade. Qualquer marginalidade em relação ao modelo deve ser recalcada, estabelecendo a primazia e o domínio da identidade em relação à diferença e do Eu em relação a outrem, estimulando o crescimento de discursos fundamentalistas e supremacistas insufladores de atos destruidores de vidas que encarnam a diferença. Portanto, assim como o pensamento da representação, que reduz a diferença à identidade, o pensamento ocidental reduziu o outro ao Eu, condenando a projeção de seu devir. O outro, porém, se recusa ao totalitarismo do Eu; logo, sua existência é vista como um ultraje, sempre oposto ao eu e "naturalmente" disposto como o negativo deste. Essa maneira de pensar, no entanto, reduziu o outro ao mesmo em prol de uma identidade absoluta, tornou-o "desviante", "marginal". Assim, fomentou a intolerância e a violência que se avoluma no século $X X I$ por quase todos os lados do planeta em relação às minorias de todo tipo, as quais são, justamente, o outro do Eu autocentrado.

Deleuze (2007) tem como um de seus empreendimentos a reversão do platonismo. O filósofo francês exalta o mundo dos simulacros. Traz à luz um mundo de diferenças livres, de devires-loucos. Se propõe a transgredir o pensamento hierárquico da representação, do $\mathrm{Eu}$, da identidade, por dentro da filosofia em perspectiva de abertura com o seu fora (DELEUZE; GUATTARI, 1992). Ousar revertêlo implica subverter não só o modelo representativo, mas a própria ideia de que é necessário um modelo para se chegar a pensar. Trata-se de revelar um mundo possível até então impossível para a representação. Um mundo de alteridades livres. Um outro mundo, mais profundo e marginal.

Segundo Deleuze (2007), o primeiro efeito de outrem é a organização de um mundo marginal: "[...] outrem assegura as margens e transições no mundo. Ele é a doçura das contiguidades e das semelhanças. Ele regula as transformações da forma e do fundo, as variações de profundidade" (DELEUZE, 2007, p. 315). O filósofo 
francês acredita que o erro das concepções existentes sobre o outro é reduzirem-no ao estado de objeto ou levá-lo ao estado de sujeito. Assim, o outro tornava-se objeto quando eu era o sujeito e não poderia se tornar sujeito sem que o Eu fosse objeto. "Mas outrem não é nem um objeto no campo de minha percepção, nem um sujeito que me percebe: é, em primeiro lugar, uma estrutura do campo perceptivo, sem a qual este campo no seu conjunto não funcionaria como o faz" (DELEUZE, 2007, p. 316).

Qual é a estrutura outrem? Para o francês, outrem revela a existência do possível. Deleuze o exemplifica como o mundo que "um rosto assustado" pode expressar. Diante de um rosto assustado, o outrem não aparece como sujeito ou objeto, mas como a possibilidade de um mundo assustador. "Um semblante assustado é a expressão de um possível mundo assustador ou de alguma coisa de assustador no mundo que ainda não vejo. [...] O mundo possível expresso existe perfeitamente, mas não existe (atualmente) fora do que o exprime" (DELEUZE, 2007, p. 317). Outrem é, logo, a expressão de um mundo possível, que possui uma realidade própria em si mesmo, enquanto possível. Basta apenas que aquele que o expressa diga "tenho medo" para que essa realidade se constitua. Portanto, "outrem é um mundo possível, tal como existe num rosto que o exprime, e se efetua numa linguagem que lhe dá uma realidade. Nesse sentido, é um conceito com três componentes inseparáveis: mundo possível, rosto existente, linguagem real ou fala"2 (DELEUZE; GUATTARI, 1992, p. 29).

Segundo Deleuze (1988, p. 414), "a estrutura de outrem e a correspondente função da linguagem representam efetivamente a manifestação do númeno, a ascensão dos valores expressivos, enfim, a tendência da diferença à interiorização". Para o autor, se há uma interiorização da diferença, ela é, portanto, outrem. Concordamos com Gallo (2008) quando afirma que a filosofia da diferença recusa o Uno e pensa o mundo como múltiplo, concedendo ao outro um novo sentido. Desse modo, torna possível o pensamento do "outro tomado enquanto tal, por si mesmo - o que significa pensar o outro como diferença" (GALO, 2008, p. 2). Seguindo o rastro

2 Enquanto escrevíamos este artigo, o mundo aterrador de violência expresso nos semblantes dos estudantes da escola de Suzano que conseguiram escapar do massacre se atualizou na realidade educacional brasileira. Até então, para nós, o exemplo de um rosto assustado, apresentado por Deleuze em Lógica do sentido (2007), remetia apenas ao romance de Tournier, Sexta-feira, ou Os limbos do Pacífico; depois do massacre na escola, ele ganhou ainda mais sentido e o conceito de outrem saltou da ficção e da filosofia para se atualizar na vida cotidiana. 
deleuziano, o outro é diferença interiorizada, encarnada, corporificada, em processo de atualização, em processo de devir. Esse pensamento é reforçado por Rolnik (1993, p. 244), para quem "a gênese do devir é sempre uma diferença e o devir é sempre um devir-outro". O outro é um ato de diferença; um produto da diferença.

Já percorrida a trilha deleuziana para a afirmação de uma nova imagem do pensamento, sem representações ou modelos, e que tome a diferença por ela mesma, questionamos: como fazer o pensamento se chocar com a diferença e com ela compor-se? Como fazê-lo operar uma desterritorialização, abrindo o processo de pensar para seu diferencial? Como fazer o outro que nos habita, a diferença que nos acomete de todos os cantos, se manifestar na escrita-pesquisa? Como lançar um devir transversal, sempre outro, que seja fruto dos outros que nos compõem, de mundos possíveis que outrem expressa, das diferenças que se atualizam em nós?

Trata-se de efetuar a terceira subtração. Após a elisão da hierarquia e do sujeito, é preciso subtrair o Uno, a identidade e a representação para fazer o múltiplo e experimentar uma escrita-pesquisa a $n-1$. Pela escrita-pesquisa, experimentamos uma vontade de desatar o pensamento e as relações acadêmicas das amarras morais da representação. Segundo Deleuze (1988), a submissão da diferença à identidade se dá por uma visão moral do mundo que exorciza o simulacro e a alteridade. Por isso, mais do que encurralar a representação e a identidade, é preciso questionar a moral, pois elas pressupõem a moral. Enquanto a moral ditar as regras, não se pode pensar a diferença, que dirá encarná-la e vivê-la, dentro e fora da universidade.

Para Deleuze (1988), foi a partir de uma visão moralista do mundo que a filosofia da representação fundou-se. Como mostramos, o filósofo se dedicou a tirar a diferença de seu estado monstruoso para fazer a filosofia funcionar de outro modo e o fez revertendo o platonismo. Com Deleuze (1988, p. 66), perguntamos: "é a diferença verdadeiramente um mal em si? Seria preciso levantar a questão em termos morais?". Para o autor, não há dúvida: o jogo humano é um jogo moral, de distribuições sedentárias, que necessita de regras categóricas e institui dicotomias. Rapidamente aprende-se a jogar esse jogo e a seguir suas regras na universidade organizada em escada, isso se se quiser nela permanecer por um tempo, claro. "Esta maneira humana, esta falsa maneira de jogar, não esconde seus pressupostos: são 
pressupostos morais, a hipótese é a do Bem e do Mal, e o jogo é uma aprendizagem da moralidade" (DELEUZE, 1988, p. 444).

Faz-se necessário, então, empreender a quarta subtração: subtrair a moral para experimentar uma escrita-pesquisa a $n-1$, além de Bem e Mal. Parece-nos que, para produzir experiências de escrita-pesquisa imanente, é imprescindível fazê-lo com forças que estão aquém e além do homem e que existem em nós. Trata-se mesmo de um processo de devir. Se alcançaremos um devir, devemos tomá-lo como é - algo que não tem ponto inicial ou estado final, mas apenas um meio -, um estado de variação que não supõe qualquer modelo nem projeta qualquer identidade (DELEUZE; GUATTARI, 1997). O devir é rizoma, bloco de coexistência (DELEUZE; PARNET, 1998). Ele constitui uma zona de vizinhança e indiscernibilidade onde devém nem um nem outro, mas o "entre" (DELEUZE; GUATTARI, 1997). Trata-se de um movimento transversal, da criação de uma transversalidade. De acordo com Deleuze e Guattari (1997, p. 83), “criações são como linhas abstratas mutantes que se livraram da incumbência de representar um mundo, precisamente porque elas agenciam um novo tipo de realidade que a história só pode recuperar ou recolocar nos sistemas pontuais".

Em nossas experiências de escrita-pesquisa, porém, não nos interessa representar o mundo acadêmico. O mundo daqueles que sabem, que ocupam um suposto lugar "de respeito" expresso em seus títulos, muito mais do que por aquilo que e como inventam, de nada nos serve para escrever e pesquisar. Na escritapesquisa imanente, operamos como cães que cavam seus buracos em uma atenção absoluta àquilo que está sendo produzido (DELEUZE; GUATTARI, 2014). As experiências de produção de escrita-pesquisa imanente em bando que vivemos até aqui, assim como estamos vivendo esta, são mobilizadas muito mais pelo não saber, por nossa ignorância associada ao desejo de aprender e inventar algo, para o qual o nosso subdesenvolvimento ajuda mais do que qualquer saber, título e posição escalonada universitária poderia contribuir. A cada vez que escrevemos, é com o nosso "terceiro mundo" que temos de nos haver. É de menos e não de mais que se trata, de uma escrileitura (CORAZZA, 2008) menor e não maior, de devir e não de ser.

O devir não é história, mas trans-histórico, intempestivo. Contra o seu tempo e a favor de um tempo por vir. É antimemória, contra a lembrança e constitui-se 
enquanto singularidade. Por essa razão, o que nasce do processo é algo inteiramente novo. Não eu ou outro como sujeitos separados, mas o devir de um novo mundo possível, de uma nova forma subjetiva. Em nosso caso, um novo modo de se relacionar na academia, com a escrita-pesquisa, assim como com os autores e livros que amamos. Segundo Manning (2016, p. 4, tradução nossa), "a forma subjetiva é a assinatura dessa singularidade. É o que agora emergiu como o sujeito do acontecimento, um sujeito nascido no processo"3. Num texto, seus sujeitos não seriam ou os escritores ou os leitores, mas uma inclusão de ambos: escrileitores, multiplicidade coletiva, rizoma. Diferença encarnada, incorporada, habitando o "entre", constituindo um ser de pura sensação. Isso é o que Deleuze e Guattari entendem como devir sensível.

O devir sensível é o ato pelo qual algo ou alguém não para de devir-outro (continuando a ser o que é). [...] Alteridade empenhada numa matéria de expressão. O monumento não atualiza o acontecimento virtual, mas o incorpora ou encarna: dá-lhe um corpo, uma vida, um universo (DELEUZE; GUATTARI, 1992, p. 229-230).

Um devir sensível emerge desse modo de fazer escrita-pesquisa e nos revela como Outros, feitos de discursos dos outros. Identidades compostas por outros. De devires sempre outros. Afirmamos, por isso, que, para a produção de uma escritapesquisa imanente, feita a muitas mãos, é preciso ter um pouco de anarquia dentro de si para 'dar luz' a esse devir. Segundo Deleuze (1988), a diferença é essa anarquia. Uma anarquia coroada. Um mundo de diferenças. Quando escrevemos, desvelamos esse mundo, pois sempre escrevemos com outros, até mesmo quando parece que escrevemos sozinhos; contudo, o mundo de diferenças se torna mais evidente e, sentimos, mais imediato, quando escrevemos juntos, em bando. Bando que precisa lidar com o problema do estilo.

\section{ENTRE O ESTILO E O NÃO ESTILO}

3 "Subjective form is the signature of this singular occasion. It is what has now emerged as the subject of the occasion, a subject born of the process" (MANNING, 2016, p. 4). 
Nos platôs da linguagem, Deleuze e Guattari tratam do estilo. Sucintamente, definem que o estilo "[...] é precisamente o procedimento de uma variação contínua" (DELEUZE; GUATTARI, 2011, p. 44). Em muitas de suas escritas solo, Deleuze também aborda o problema do estilo ao tratar de procedimentos artísticos, tais como a música, a pintura, a literatura, o cinema. Isso se apresenta, por exemplo, em Proust e os signos (2010), quando, ao tratar de literatura, o conceito é definido como um "não estilo":

É um não estilo porque se confunde com o "interpretar" puro e sem sujeito e porque multiplica os pontos de vista sobre a frase, no interior da frase. [...] $\mathrm{O}$ estilo é a explicação dos signos em diferentes velocidades de desenvolvimento, segundo as cadeias associativas que lhes são próprias, atingindo em cada um deles o ponto de ruptura da essência como ponto de vista; daí o papel dos incidentes, das subordinadas, das comparações que exprimem numa imagem o processo de explicação, a imagem sendo boa quando explica bem, sempre explosiva, sem nunca se sacrificar à pretensa beleza do conjunto (DELEUZE, 2010, p. 158).

Para abordarem o problema do estilo na escrita, nos platôs da linguagem, de modo especial, os autores o vinculam ao agenciamento de enunciação que, desde Kafka: Por uma literatura menor (2016), é sempre coletivo. Na condição de um procedimento de variação contínua, ele, necessariamente, se diferencia de uma criação psicológica individual. É o estilo que faz fugir a linguagem, tornando-a intensiva, "puro contínuo de valores e intensidades" (DELEUZE; GUATTARI, 2011, p. 45).

Quinta subtração para escrever a $n-1$ e alcançar um estilo ou, preferimos, um não estilo: subtrair a perspectiva psicológica individual. Em O que é filosofia?, Deleuze e Guattari (1992) pensam o estilo em filosofia, nas artes e na ciência. Importa-nos, aqui, pensar o conceito de estilo em filosofia. Nesse plano do pensamento, o estilo aparece como o movimento do conceito, ou melhor, o tratamento dado ao conceito de uma maneira que o faça variar e ganhar uma forma no tempo e no espaço, de modo diferente do que era anteriormente ou até mesmo de modo inédito que faça surgir algo novo. O filósofo cria quando tomado pelo devir, que pode ser aprendido ou acelerado em variação contínua. Ao escrever, necessariamente, "é preciso o estilo - a sintaxe de um escritor" (DELEUZE; GUATTARI, 1992, p. 220), pois, ao escrever, ele "[...] se 
serve das palavras, mas criando uma sintaxe que as introduz na sensação, e que faz gaguejar a língua estrangeira na língua" (DELEUZE; GUATTARI, 1992, p. 228).

Sobre o estilo na escrita filosófica, Deleuze trata também em Conversações (2013), quando apresenta os grandes filósofos como grandes estilistas, aqueles que imprimem movimento ao conceito, dando vida à escrita ao fazer a língua variar, gaguejar no encontro com um fora:

\footnotetext{
O estilo em filosofia é o movimento do conceito. Certamente, este não existe fora das frases, mas as frases não têm outro objetivo que não o de dar-lhe vida, uma vida independente. O estilo é a variação da língua, uma modulação e uma tensão de toda a linguagem em direção a um fora. Em filosofia é como em um romance: deve-se perguntar "que vai suceder?", "o que se passou?". Só que os personagens são conceitos, e os meios, as paisagens, são espaços-tempos. Escreve-se sempre para dar a vida, para liberar a vida aí onde ela está aprisionada, para traçar linhas de fuga (DELEUZE, 2013, p. 180).
}

Nesse sentido, o exercício da pesquisa-escrita em bando que também realizamos neste artigo e é seu "objeto de fundo", precisa aproximar-se do conceito de estilo. Nos parece que, quando Deleuze e Guattari tratam da criação a partir da ideia de agenciamento, encontramos o outro ali suposto, uma vez que o agenciamento é sempre coletivo. Assim, ele também pulula em nossas experiências de escrever o discurso de outros, com outros. Ademais, os agenciamentos coletivos de enunciação podem liberar passagens, na linguagem, que permitam a produção de um não estilo.

Para que o conceito filosófico atinja uma variação, contudo, é preciso que a linguagem não seja concebida como um sistema homogêneo. Um pesquisadorescritor, escrileitor, que abdicou dos modelos e da identidade impostos pela imagem de pensamento moral da representação, porque sente e afirma a diferença como primeira, não tem ilusões de homogeneidade e equilíbrio sequer na língua. Concebea como agenciamento heterogêneo em perpétuo desequilíbrio. $E$, naquilo que ela tem, aparentemente, de sistema homogêneo, cava diferenças potenciais, coloca variáveis em variação, tornando possível que "entre" essas diferenças algo se passe, a ponto de fazer "surgir um clarão que sai da própria linguagem, fazendo-nos ver e pensar o que permanecia na sombra em torno das palavras, entidades de cuja existência mal suspeitávamos" (DELEUZE, 2013, p.180).

Esse "cavar diferenças" é feito por meio do que Deleuze e Guattari chamam de estilo. Dito de outro modo, o estilo é a "modulação da língua", aquilo que a "tensiona", 
o que não pode ser realizado senão por meio da "polifonia dos sujeitos de enunciação" (DELEUZE, 2016c, p. 390-391). O estilo não é, porém, uma noção tranquila, ela ainda nos escapa. Mesmo Deleuze a considerava "difícil" (DELEUZE, 2016c, p. 392). Talvez, se nos ocuparmos daquilo que a ele se opõe, nos ajude. Diz Deleuze (2016c) que são duas coisas: a homogeneidade da língua e o seu oposto em excesso, a heterogeneidade em demasia.

De um lado, a língua, tomada como sistema homogêneo, aprisiona-a. Conceber a língua como sistema absolutamente estratificado, centralizado e unificado - imagem arbórea também da língua - barra desejos e impede a produção. Os principais estratos são o organismo, a significância, a interpretação, a subjetivação e a sujeição que, para produzirem um estilo, precisam ser abstraídos. Sexta operação em $n-1$, portanto, vez que são eles os impeditivos da positividade potencial dos devires, da efetivação da linha de fuga, pois são aqueles estratos que impedem a linha de fuga de promover desterritorializações e alcançar sua potência absoluta. Por isso, o problema de que tratam Deleuze e Guattari é o de como tornar possível o agenciamento de enunciação, que é sempre coletivo, como vimos com Bakhtin, mais favorável, "fazê-lo passar, de sua face voltada para os estratos, à outra face voltada para o plano de consistência ou para o corpo sem órgãos" (DELEUZE; GUATTARI, 2011, p. 94). Face essa que, para os limites de nossa compreensão, chamamos de Aberto do mundo, o não estratificado.

De outro lado, o segundo elemento que se opõe ao estilo ocorre por meio do excesso de heterogeneidade, ou seja, quando ela "é tão grande que se torna indiferença, gratuidade, e que nada de preciso passa entre os polos" (DELEUZE, 2013, p. 180). Nesse caso, é fácil compreender por que se faz tão importante, imprescindível até, para Deleuze, a história da filosofia, pois o tratamento dos conceitos e o desenvolvimento do não estilo somente faz-se possível quando o escritor é atravessado por materiais que ele seleciona e põe em composição, a partir de encontros com o que é específico da filosofia. Talvez possamos afirmar que a história da filosofia seja a transversal que possibilita as passagens e força uma conexão entre uma palavra e outra, um conceito e outro, como o zigue-zague de que fala Deleuze (2013, p.180): 
Entre uma oração principal e uma subordinada tem que haver uma tensão, uma espécie de zigue-zague, mesmo e sobretudo quando a frase parece toda correta. Há um estilo quando as palavras produzem um clarão que vai de umas às outras, mesmo que muito afastadas.

Partindo dessa visão, nos perguntamos: como pesquisar-escrever filosofia fazendo fugir a linguagem, de forma intensa, agarrando-se, também, nas linhas de fuga? Como produzir a variação contínua da língua e da filosofia, criando um estilo, ou melhor, um não estilo, ao colocar os conceitos em movimento? Como escapar da linguagem homogênea e não cair em uma heterogeneidade completa que não permita o estabelecimento de conexões e a produção de sentidos?

Ao pensarmos amparados pelos escritos de Deleuze e Guattari, podemos afirmar a ideia de que partimos de referenciais advindos da filosofia, mas também de outros campos de conhecimento, sem que haja, no entanto, algo pronto, prédeterminado, nenhum princípio originário ou fundamento, nenhuma verdade absoluta, das quais devamos partir para pesquisar-escrever. Não existem trilhos feitos, já trilhados, pois "a verdade é da ordem da produção da existência. Não está dentro da cabeça, é algo que existe. O escritor emite corpos reais" (DELEUZE, 2013, p.172). Portanto, se lidamos com materiais, corpos reais, é deles que se parte para construir os próprios trilhos. No nosso caso, são trilhos ad hoc. Depois de feitos e trilhados, trata-se de fazer outros. Alguns perfis de aço e dormentes dos trilhos já trilhados são reaproveitados, mas novos precisam ser introduzidos, fabricados, a fim de realizar uma nova escrita-pesquisa que seja realmente nova, ao menos para nós. Na filosofia, lidamos com os conceitos criados e tratados pela tradição, por isso, como afirmamos anteriormente, é ela que atravessa toda a produção filosófica e permite a construção do pensamento com sentido.

Para melhor compreender, podemos fazer uso da "ideia do saco", que aparece em Diálogos: "Ter um saco onde coloco tudo o que encontro, com a condição de que me coloquem também em um saco" (DELEUZE, 1998, p. 16). Buscar um estilo de pesquisa-escrita em bando é isto: todos colocam em um único saco o conhecimento de cada um e que cada pesquisador armazenava em seu saco individual (que, por si só, já é uma multiplicidade). Todos despejam o material que carregam em um grande saco (no nosso caso, um arquivo docs). Dentro do saco está a anarquia, a polifonia, o material variado, o desconexo, o colorido, o livre, o heterogêneo. É nesse sentido 
que estamos pensando a busca pelo estilo, ou melhor, o não estilo. Aproximar-se do não estilo começa por novos encontros, com materiais outros, despejados de um grande saco. E é exatamente devido a esse modo anárquico de escolher materiais de trabalho que pesquisar-escrever em bando implica perigos e alegrias.

Ser um "bando": os bandos vivem os piores perigos, reformar os juízes, tribunais, escolas, famílias e conjugalidades, mas o que há de bom em um bando, em princípio, é que cada um cuida de seu próprio negócio encontrando ao mesmo tempo os outros; cada um tira seu proveito, e que um devir se delineia, um bloco, que já não é de ninguém, mas está "entre" todo mundo, se põe em movimento como um barquinho que crianças largam e perdem e os outros roubam. (DELEUZE, 1998, p. 17).

Escrever é estar no deserto ou mesmo ser deserto, como diz Deleuze (1998, p. 19): "nós somos desertos, mas povoados de tribos, de faunas e floras. Passamos nosso tempo a arrumar essas tribos, a dispô-las de outro modo, a eliminar algumas delas e fazer prosperar outras". Essa é a experimentação sobre si mesmo, as combinações que nos habitam, o que mais próximo temos de uma "identidade". Em bando, a pesquisa-escrita não se diferencia por trabalharmos em grupo, mas, por trabalharmos com o que se passa "entre" nós, a experimentação se passa no campo do "entre". É isso que aprendemos com a escrita de Deleuze feita com Guattari: o que acontece "entre" os dois é o que interessa. Como diz Deleuze sobre esse encontro com Guattari: “O deserto crescia, mas povoando-se ainda mais" (DELEUZE, 1998, p. 25). As nossas escritas cruzadas, emendadas, riscadas, rasuradas, acrescentadas, anuladas, esquecidas, resgatadas, reformuladas, tratadas, tendem para a variação.

Nossos exercícios de pesquisa-escrita em bando tornaram-se um modo de invenção que realiza um esforço conjunto na busca por um não estilo. Nesses exercícios, roubamos as linhas uns dos outros, com intenção de fazer passar algo nas entrelinhas, uma variação que permita um tratamento diferenciado de conceitos da filosofia. Esse tratamento faz com que a forma da pesquisa-escrita fique subordinada ao desenvolvimento coletivo de sua produção, se estendendo ao conjunto retirado de todos os "sacos" ali dispostos, liberando a variação. Quando a variação é liberada, algo novo pode surgir.

O estilo, então, tem necessidade de muito silêncio e trabalho para produzir um turbilhão no mesmo lugar, depois, lança-se como um fósforo que as crianças vão seguindo na água da sarjeta. Pois certamente não é compondo 
palavras, combinando frases, utilizando ideias que se faz um estilo. É preciso abrir as palavras, rachar as coisas, para que se liberem vetores que são os da terra (DELEUZE, 2013, p.172).

Para compreender essa busca por um processo de variação contínua, que pode ser pensado como um não estilo, faz-se importante reconhecer que este somente se torna possível através dos agenciamentos. O estilo é "[...] um agenciamento, um agenciamento de enunciação. Conseguir gaguejar em sua própria língua, é isso um estilo" (DELEUZE; PARNET, 1998, p.12). A produção da diferença, a gagueira, necessita dos agenciamentos para existir, agenciamentos coletivos sem sujeito nem objeto, "mas estados maquínicos" que nada mais são do que o próprio processo de produção e a potencialidade que dele resulta (DELEUZE; PARNET, 1998, p. 58). No modo de escrita em bando que experienciamos, percebe-se que as funções entre um agenciamento e outro são variáveis, entrecruzam-se continuamente, misturando seus valores, seus segmentos, seus objetos. Parece-nos que é exatamente essa maquinação que faz com que algo novo se passe, ao menos novo em e para nós.

É nos picos de desterritorialização do agenciamento conjugados pelo escritor, artista, cientista, que se constituem os pontos de criação ou de potencialidade. "Tudo foge, tudo cria, mas jamais sozinho" (DELEUZE; GUATTARI, 2011, p. 106). Por isso, cria-se um estilo quando se é capaz de subtrair a perspectiva psicológica individual. Esse estilo passa a ser um não estilo exatamente porque é coletivo e aberto, pois quando alguém (cientista, escritor, filósofo, artista) age sobre determinada matéria, parte de uma multiplicidade da qual resultará um mapa, linhas serão delineadas e traçadas, possibilitando uma multiplicidade de novas conexões.

Quando a variação se torna contínua, quando ocorrem os agenciamentos, com eles os mapas são traçados e os rostos são produzidos. Assim, "um estilo, que pode ser a coisa mais natural do mundo, é precisamente o procedimento de uma variação contínua" (DELEUZE; GUATTARI, 2011, p. 44). E mais: os estilos podem ser pensados como "visões paradas no tempo e no espaço" (DELEUZE; GUATTARI,1992, p. 222), que nos permitem reconhecer um escrito como sendo de Aristóteles, outro de Kant, de Nietzsche ou de Deleuze, cada um com seu estilo, isso para ficar em casos/mapas/rostos da filosofia, que é o nosso território de partida.

\section{ENTÃO ERA ISSO!}


Por muito tempo estudamos a filosofia de Deleuze: primeiro, fizemos as composições que diziam respeito aos interesses de cada um e escrevemos, individualmente; depois, demos a ler nossas escritas à orientadora; a seguir, retomamos a escrita que já não podia mais ser dita "é minha", pois nela já havia traços de outras mãos; e, por último, demos a ver essa escrita ao "bando" de orientação, para apreciar, avaliar, ponderar, indicar rumos para a finalização da pesquisa. Sempre tivemos a garantia de leitores atentos e, ao mesmo tempo, cuidadosos e severos. Juntos aprendemos a ser tudo isso, até que nos coube a exposição do "platô impossível", aquele terceiro que responde à questão "Quem a Terra pensa que é?" (DELEUZE; GUATTARI, 2004).

Lemos esse "platô" sozinhos, cada um separado do outro. À época, éramos seis, e a impossibilidade só se confirmava, até que passamos a lê-lo juntos e a cada um tentar dizer, para os outros, a partir das investigações já feitas, o que conseguia decifrar. Assim, clarões foram aparecendo e composições foram sendo feitas. Depois, convidamos um especialista em biologia, também formado em filosofia, aberto para a aventura de Deleuze e Guattari. E mais: nos encorajamos a escrever em bando, pois sentíamos que não o conseguiríamos fazer sozinhos. Recorremos ao Google Docs que foi apenas meio para que pudéssemos inventar uma escrita em bando. Para nós, se tratava de novidade, mas, sabíamos, é um meio comum entre os grupos de pesquisa, ao menos das "ciências exatas" de nossa universidade.

O diferencial da experiência, porém, não estava ali, mas nas relações que estabelecemos durante o processo: tínhamos um território comum e demarcamos as partes onde cada qual faria o "seu buraco"; contudo, de repente, os "buracos" começaram a se encontrar. Não havia mais orientadora, mestrandos, doutorandos, ex-orientandos. Eram apenas escrileitores dedicados, absolutamente, a uma escritapesquisa coletiva. Assim, de repente, aconteceu a experiência da imanência, como nunca antes tínhamos experimentado na academia. Avaliamos, sem pretensão e autoelogio algum, que, ao menos no processo de produção, fizemos o múltiplo; e a lógica do $n-1$ passou a ser experimentada, sem que nos déssemos conta disso. Tomamos, no entanto, consciência dela apenas na experiência de escrileitura deste artigo. 
Agora, se era exatamente esse o sentido da fórmula do $n-1$ que Deleuze e Guattari tinham em mente, não sabemos. Para nós, ela funcionou assim: subtraímos a hierarquia, o sujeito autocentrado, o uno, a identidade e a representação, a moral, a perspectiva psicológica individual e os estratos que aprisionam a variação da língua. A partir disso, o "então era isso!" apareceu várias vezes no processo de produção e um ajudou o outro, com suas intervenções, a perceber e produzir sentido no que até então não havia. Por óbvio, doses de sem-sentido também surgiram com algumas interrogações de cursores coloridos que apareciam no mesmo parágrafo do arquivo e novos sentidos foram produzidos.

Se inventamos um não estilo entre nós? Não sabemos. O mais provável é que não. Avaliamos, contudo, que se produziu um outro "mundo possível" para o "perfil" do pesquisador-escritor em filosofia, ao menos para este bando. Mundo incomum nessa área, é verdade. Afinal, "duplas” são raras em filosofia. Temos Marx e Engels; Adorno e Horkheimer; Deleuze e Guattari; Negri e Hardt. Por isso afirmamos, por experiência própria, que em filosofia também é possível escrever com mais do que duas ou quatro mãos e produzir, transversalmente, sentidos, pesquisas, artigos, publicações, mas, sobretudo, modos imanentes de viver - na universidade - que marcarão a vida de cada um que passou por essa experiência. Não sabemos se elas se repetirão com outras combinações de pesquisadores, talvez tenha sido só um lance de sorte.

\section{ESTER MARIA DREHER HEUSER}

Doutora em Educação pela UFRGS. Professora Associada do Centro de Ciências Humanas e Sociais, PPG - Filosofia (Mestrado e Doutorado) - UNIOESTE/Campus Toledo/PR.

\section{ADRIANA MUNIZ DIAS}

Professora de Filosofia e História na rede pública do Estado do Paraná. Mestre em Filosofia pela UNIOESTE.

\section{ROBERTO CORRÊA SCIENZA}

Doutorando na Linha de Ética e Filosofia Política do PPG-Filosofia da UNIOESTE. Bolsista na Fundação Araucária. 


\section{Atos de Pesquisa em Educação - ISSN 1809-0354 \\ Blumenau, v.14, n.3, p.982-1005, set./dez. 2019 \\ DOI: http://dx.doi.org/10.7867/1809-0354.2019v14n3p982-1005}

\section{REFERÊNCIAS}

BAKHTIN, M. Problemas da Poética de Dostoiévski. Tradução de Paulo Bezerra. Rio de Janeiro: Forense Universitária, 2013.

BAKHTIN, M. Marxismo e filosofia da linguagem. Tradução de Michel Lahud e Yara Frateschi Vieira. São Paulo: Hucitec, 2006.

BAKHTIN, Mikhail. Estética da criação verbal. Tradução de Maria Emantina Galvão G. Pereira. 2. ed. São Paulo: Martins Fontes, 1997.

CORAZZA, S. M. Os cantos de Fouror: escrileitura em filosofia-educação. Porto Alegre: Sulina, 2008.

DELEUZE, G. Diferença e Repetição. Tradução de Luiz Orlandi e Roberto Machado. Rio de Janeiro: Graal, 1988.

DELEUZE, G. Lógica do Sentido. Tradução de Luiz Roberto Salinas Fortes. São Paulo: Perspectiva, 2007.

DELEUZE, G. Proust e os signos. Tradução de Antônio Piquet e Roberto Machado. Rio de Janeiro: Forense Universitária, 2010.

DELEUZE, G. Conversações. Tradução de Peter Pál Pelbart. São Paulo: Editora 34, 2013.

DELEUZE, G. Os rincões de imanência. In: DELEUZE, G. Dois regimes de loucos: textos e entrevistas (1975-1995). Tradução de Guilherme Ivo. São Paulo: Editora 34, 2016a, p. 277-280.

DELEUZE, G. Prefácio: uma nova estilística. In: DELEUZE, G. Dois regimes de loucos: textos e entrevistas (1975-1995). Tradução de Guilherme Ivo. São Paulo: Editora 34, 2016b, p. 388-394.

DELEUZE, G. A imanência: uma vida... In: DELEUZE, G. Dois regimes de loucos: textos e entrevistas (1975-1995). Tradução de Guilherme Ivo. São Paulo: Editora 34, 2016c, p. 407-413.

DELEUZE, G.; GUATTARI, F. O que é a Filosofia? Tradução de Bento Prado Jr. e Alberto Alonso Muñoz. Rio de Janeiro: Editora 34, 1992.

DELEUZE, G.; GUATTARI, F. Mil Platôs: capitalismo e esquizofrenia. Tradução de Suely Rolnik. São Paulo: Editora 34, 1997, vol. 4.

DELEUZE, G.; GUATTARI, F. Mil platôs: capitalismo e esquizofrenia. Tradução de Aurélio Guerra Neto e Célia Pinto Costa. Rio de Janeiro: Editora 34, 2004, v. 1.

DELEUZE, G.; GUATTARI, F. Mil platôs: capitalismo e esquizofrenia. Tradução: Ana Lúcia de Oliveira e Lúcia Cláudia Leão. Rio de Janeiro: Editora 34, 2011, v. 2. 
DELEUZE, G.; GUATTARI, F. Kafka: Por uma literatura menor. Tradução: Cíntia Vieira. Belo Horizonte: Autêntica, 2014.

DELEUZE, G.; PARNET, C.. Diálogos. Tradução: Eloisa Araújo Ribeiro. São Paulo: Escuta, 1998.

GALLO, S. Eu, o outro e tantos outros: educação, alteridade e filosofia da diferença. Congresso Internacional Cotidiano: Diálogos sobre Diálogos, 2. 2008, Rio de Janeiro. Anais... Rio de Janeiro: Universidade Federal Fluminense, 2008.

MANNING, E. For a Pragmatics of the Useless, or the Value of the Infrathin. SAGE Publications, New York, p. 1-19, 2016.

MARQUES, M. P. Platão, pensador da diferença: uma leitura do Sofista. Belo Horizonte: UFMG, 2006.

PLATÃO. A República. Tradução de Carlos Alberto Nunes. 3. ed. Belém: EDUFPA, 2000.

ROLNIK, Suely. Pensamento, corpo e devir: Uma perspectiva ético/estético/política no trabalho acadêmico. Cadernos de Subjetividade, São Paulo, v. 1, n. 2, p. 241-25, set./fev. 1993. 